\title{
Comparison of condylar position in normal occlusion, Class II Division 1, Class II Division 2 and Class III malocclusions using CBCT imaging
}

\author{
Pilar Rivero-Millán ${ }^{1}$, Jose-Maria Barrera-Mora ${ }^{2}$, Eduardo Espinar-Escalona ${ }^{3}$, Carlos-Antonio González-del \\ Pino ${ }^{4}$, Domingo Martín-Salvador ${ }^{5}$, Jose-Maria Llamas-Carreras ${ }^{6}$
}

\author{
${ }^{1}$ Dental Surgeon (DDS). University of Sevilla \\ ${ }^{2}$ Doctoral Degree $(\mathrm{PhD})$. Assistant Professor. University of Sevilla \\ ${ }^{3}$ Doctoral Degree $(\mathrm{PhD})$. Titular Professor. University of Sevilla \\ ${ }^{4}$ Expert in statistics applied to health sciences \\ ${ }^{5}$ Doctoral Degree (PhD). Domingo Martin Salvador. Visiting Professor. The Complutense University of Madrid \\ ${ }^{6}$ Doctoral Degree $(\mathrm{PhD})$. Lecturer. University of Seville
}

\section{Correspondence: \\ University of Sevilla \\ jmbmora@us.es}

Received: 10/09/2021

Accepted: $11 / 10 / 2021$
Rivero-Millán P, Barrera-Mora JM, Espinar-Escalona E, González-del Pino CA, Martín-Salvador D, Llamas-Carreras JM. Comparison of condylar position in normal occlusion, Class II Division 1, Class II Division 2 and Class III malocclusions using CBCT imaging. J Clin Exp Dent. 2021;13(12):e1216-26.

\begin{tabular}{|c|}
\hline 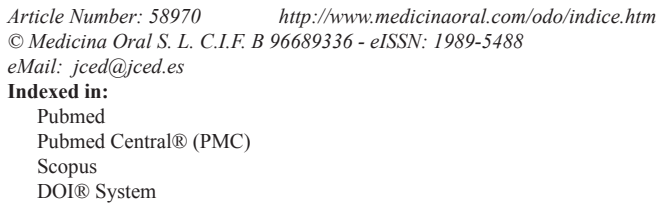 \\
\hline
\end{tabular}

\begin{abstract}
Background: The aim of this study was to establish the condylar position in a group of patients with normal occlusion, compared to Class II Div 1, Class II Div 2 and Class III malocclusions using CBCT imaging.

Material and Methods: Retrospective case-control study carried out by analyzing CBCT images of 80 patients. The sample was divided into 4 different groups with 20 patients each (40 TMJ). All patients were positioned using the Frankfurt plane, parallel to the floor and in maximum intercuspation. The control group included asymptomatic patients with normal occlusion (Less than $2 \mathrm{~mm}$ of tooth size-arch length discrepancy, positive or negative, $0-2 \mathrm{~mm}$ overjet, $2-4 \mathrm{~mm}$ overbite, less than 15 o rotations, without facial asymmetries, no previous orthodontic or occlusal treatment, without muscular or articular signs or symptoms in both TMJs) and the experimental group with (class II/1, II/2 and III) malocclusions.

Results: The group with normal occlusion had the condyles centrally positioned within the glenoid fossa. The values obtained in this group were considered as optimal and when compared with the other groups with malocclusions. The results established that the position of the condyle was more posterior in class II/2 and more superior in class III patients than the asymptomatic normal occlusion group.

Conclusions: The data obtained in the asymptomatic group with normal occlusion could be used as a reference for future studies. The comparison of these values with those obtained from analyzing the different sagittal malocclusions show significant differences that could be valuable when establishing the diagnosis and the objectives of the treatment plan in orthodontics.
\end{abstract}

Key words: Condylar position, CBCT, dental malocclusion and condylar concentricity. 


\section{Introduction}

The role of the condylar position in the correct functioning of the stomatognathic system has been the center of study and controversy throughout the history of dentistry.

The published literature includes several articles that focus on determining if the condylar concentricity could be the optimum position and whether an eccentricity could be a determining factor in the development of temporomandibular joint (TMJ) disorders.

The scientific discussion is inevitably linked to the use of different diagnostic techniques. In the past, the limitations of the diagnostic techniques that were available made it difficult to study the TMJ, as they only allowed the use of two-dimensional images with a large radiation dose.

The radiographic techniques used to study the TMJ improved greatly thanks to researchers such as Pordes (1), Updegrave (2), Grewcock or Lindblom (3). The development of the cephalometry of Broadbent (4) in 1931, which was later used by several authors such as Gillis (5) or Reisner (6), allowed the measurement of the changes that occur in the mandible in comparison to the rest of the cranium. The use of the laminography by authors such as Brader (7) or Ricketts (8-10), led to improvements in the analysis of the mandibular growth.

The advent of three-dimensional diagnostic techniques allowed us to obtain much more precise images. However, the most precise images were obtained when the cone beam computerized tomography (CBCT) became available, which gave high resolution three dimensional images that allowed the assessment and quantification of the facial osseous tissues in real dimensions (1:1 proportion) with no significant magnification or distortion (11), and therefore giving greater anatomical precision (12). It also implied lower cost, lower radiation dose and lower acquisition time than conventional computerized tomography $(\mathrm{CT})(13,14)$.

Despite magnetic resonance imaging (MRI) being considered the gold standard technique to compare soft tissues and visualize complex movements of the disc in multiple views (15-18), CBTC obviously provides some advantages in comparison. Its greater availability, lower cost and higher precision in demonstrating hard tissue components have made the CBCT an acceptable imaging technique to assess the TMJ. Therefore, it provides unique characteristics to daily orthodontic practice (19). When reviewing some of the most outstanding studies on this topic, authors such as Farrar and Mc Carty $(20,12)$ or Lindblom $(22)$ linked the eccentricity of the condyle with the presence of TMJ disorders. Similarly, authors such as Rokni (23) or Weinberg (24) suggested that the condylar concentricity was the ideal position. Pullinger (25) studied asymptomatic subjects and concluded that, despite $50-65 \%$ of the condyles being in concentric position, there were also patients without concentric condyles that did not suffer from TMJ disorders.

In 1982, After reviewing the literature, the American Dental Association (ADA) concluded that there was insufficient scientific evidence to relate an eccentricity and the presence of TMJ disorders (26).

However, in the following years several studies, such as Cholasueka et al. (27) or Incesu et al. (28), linked a posteriorly positioned condyle with joint disorders.

Rodrigues et al. $(29,30)$, described how the functional load applied to the TMJ can influence its morphology. This load can vary depending on the dento-facial morphology of the subject. Therefore, it can be suggested that both condyle and mandibular fossa will vary in shape in patients with different malocclusions.

The aim of this study was to further investigate the three dimensional condyle position in the glenoid fossa of patients with normal occlusion in comparison to patients that suffer from different types of malocclusion.

\section{Material and Methods}

A non-experimental cross-sectional study was carried out with case-control methodology, which included 4 groups with 20 patients each (40 joints). The control group included asymptomatic patients with normal occlusion and the other three groups included patients with different malocclusions (class II/1, class II/2 and class III). In total, 80 patients were included in the sample, with a total of $160 \mathrm{TMJ}$ (since both joints were analyzed, right and left). The inclusion and exclusion criteria are shown in Tables 1 and 2.

The program that has been used to perform the measurements is In Vivo Anatomage ${ }^{\circledR}$, allows obtaining highly accurate quantitative measurements. All CBCTs have been analyzed by the author of the work, previously trained. In addition, to provide internal validity to the measurements taken, we have carried out the intraclass relationship coefficient (ICC). A result of 0.82 was obtained, indicating agreement.

To reach a confidence level of $95 \%$ and a statistical power of $80 \%$ in the analysis of independent groups, it is necessary a sample of 20 individuals in each group. For intragroup analysis and to achieve the same confidence and power levels, only 12 individuals were required per group.

Hence, we select a sample of 20 individuals per group to cover both scenarios.

CBCT scans were not carried out for the purpose of this study. They were obtained in previous orthodontic or multidisciplinary consultations in a private orthodontic practice. All CBCT scans were performed in the same radiographic center using a Kodak 9500 machine and using the S3D Imaging Software.

All patients were positioned using the Frankfurt plane, 
Table 1: Inclusion criteria.

\begin{tabular}{|c|c|}
\hline \multicolumn{2}{|c|}{ INCLUSION CRITERIA } \\
\hline NORMAL OCCLUSION GROUP & MALOCCLUSION GROUPS (CLASS II/1, II/2 AND III) \\
\hline $\begin{array}{l}\text { Age: } 16 \text { years or older. } \\
\text { Bilateral Angle Class I, both molar and canine. } \\
\text { Wits Appraisal matching a class I } \\
\text { Less than } 2 \mathrm{~mm} \text { of tooth size-arch length discrepancy, } \\
\text { positive or negative. } \\
0-2 \mathrm{~mm} \text { overjet. } \\
2-4 \mathrm{~mm} \text { overbite. } \\
\text { Less than } 15^{\circ} \text { rotations. } \\
\text { Without facial asymmetries. } \\
\text { No previous orthodontic or occlusal treatment. } \\
\text { Without muscular or articular signs or symptoms in both } \\
\text { TMJs. } \\
\text { Previous CBCT image available }\end{array}$ & $\begin{array}{l}\text { Age: } 16 \text { years or older. } \\
\text { Dental and skeletal malocclusion that matches the maloc- } \\
\text { clusion group it belongs to, following both Angle and Wits } \\
\text { Appraisal criteria } \\
\text { No previous history of orthodontic treatment. } \\
\text { Previous CBCT image available. }\end{array}$ \\
\hline
\end{tabular}

Table 2: Exclusion criteria.

\begin{tabular}{|c|c|}
\hline \multicolumn{2}{|c|}{ EXCLUSION CRITERIA } \\
\hline NORMAL OCCLUSION GROUP & $\begin{array}{c}\text { MALOCCLUSION GROUPS } \\
\text { (CLASS II/1, II/2 AND III) }\end{array}$ \\
\hline $\begin{array}{c}\text { Under } 16 \text { years old. } \\
\text { Previous orthodontic or occlusal treatment. } \\
\text { Without a CBCT image. } \\
\text { Without Angle Class I molar and canine. } \\
\text { More than } 2 \mathrm{~mm} \text { of tooth size-arch length discrepancy. } \\
\text { Anterior or posterior crossbite. } \\
\text { Presence of articular signs or symptoms. } \\
\text { Overjet greater than } 2 \mathrm{~mm} \text { or smaller than } 0 \mathrm{~mm} \text {. } \\
\text { Overbite greater than } 4 \mathrm{~mm} \text { or smaller than } 2 \mathrm{~mm} \text {. } \\
\text { Rotations of more than } 15^{\circ} \text {. }\end{array}$ & $\begin{array}{l}\text { Under } 16 \text { years old. } \\
\text { Previous orthodontic treatment. } \\
\text { Without an initial or final CBCT image. } \\
\text { Cross bites (except for group 3) }\end{array}$ \\
\hline
\end{tabular}

parallel to the floor and in maximum intercuspation. All CBCT images were exported as Dicom files and digitalized using In Vivo Dental Anatomage 5 Software, which allows the identification of reference points with great precision and the selection of the view point; it also provides very precise quantitative measurements.

The obtained data was incorporated in an Excel file that was created and codified specifically for the purpose of this study, and that was transformed into a SAV file for statistical interpretation using the software SPSS 24. Statistical hypothesis testing involved an initial normality test of the quantitative variables using the Kolmogorov Smirnov and Shapiro Wilks tests. Since the variables followed a normal distribution, parametric tests were used. Quantitative variables were compared using the Pearson correlation coefficient for normalized variables.
The mean of variables that were both quantitative and categorical were compared using Student's T Test if there were only 2 means, or the ANOVA test if there were more than 2 means.

The study sample included 57 women $(71.3 \%)$ and 23 men $(28.7 \%)$. The only group that included more male than female patients was the one with class III subjects. The mean age of the sample was 30.15 years with a standard deviation of \pm 10.93 years.

When analyzing the intraclass correlation coefficient, the intra-observer variability was 0.82 , which shows a good level of conformity (31).

All the CBCT images that were analyzed required establishing the Frankfurt plane and reorienting it parallel to the floor. The J point was also determined in the axial plane (union point between the vomer and sphenoid bo- 
nes) (11), as well as the midpoint of the condyle in both axial and coronal planes (Figs. 1,2). Once the midpoint of the condyle had been established, the sagittal measurements were registered ((Fig. 3, Tables 3,4). Finally, the condylar concentricity was analyzed using the formula described by Pullinger and Hollenger (25), (Fig. 4).
Posterior interarticular distance - anterior interarticular distance Posterior interarticular distance + anterior interarticular distance $\mathrm{x} 100 \%$

Fig. 4: Formula used to obtain the condylar concentricity. Pullinger AG, Hollender L et al.A. A tomographic study of mandibular condyle position in an asymptomatic population. J Prosthet Dent. 1985;53(5):706-13.

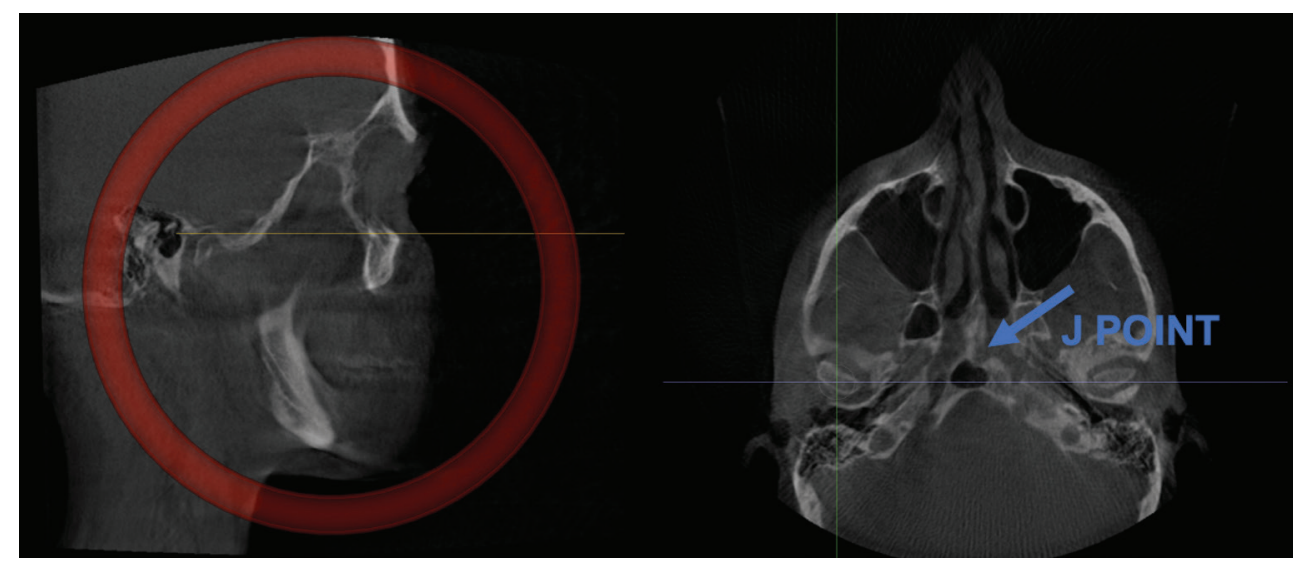

Fig. 1: Frankfurt plane parallel to the floor and determination of the J point.

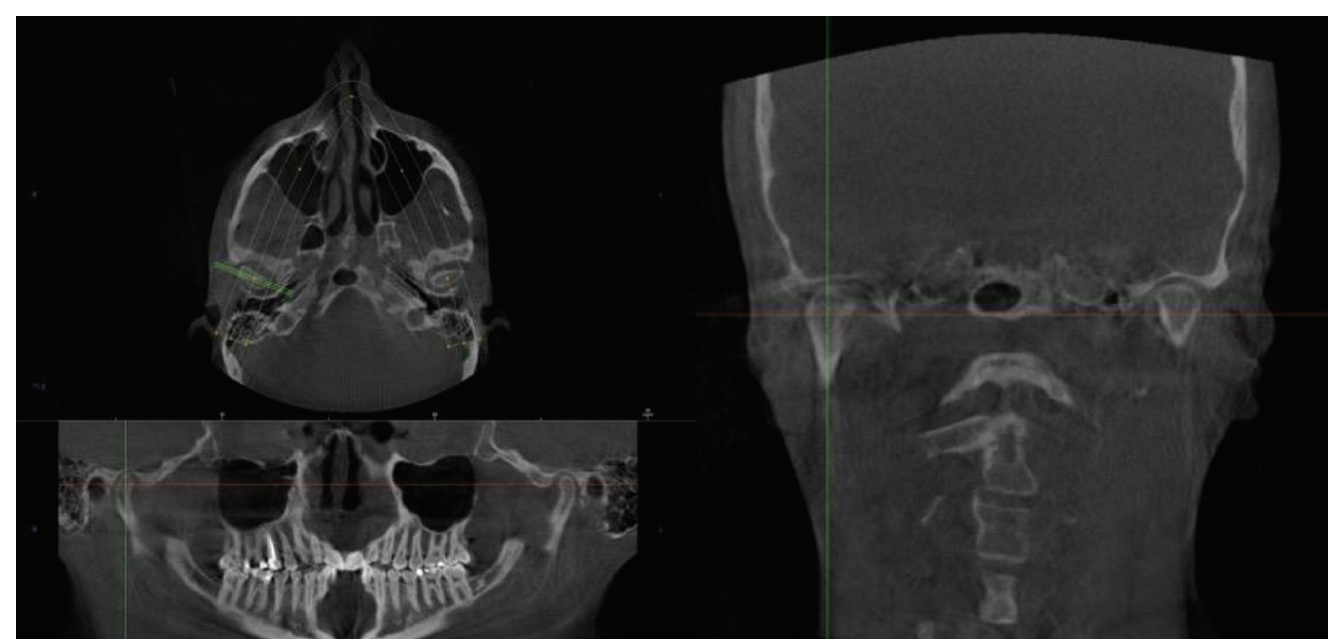

Fig. 2: Determination of the midpoint of the condyle.

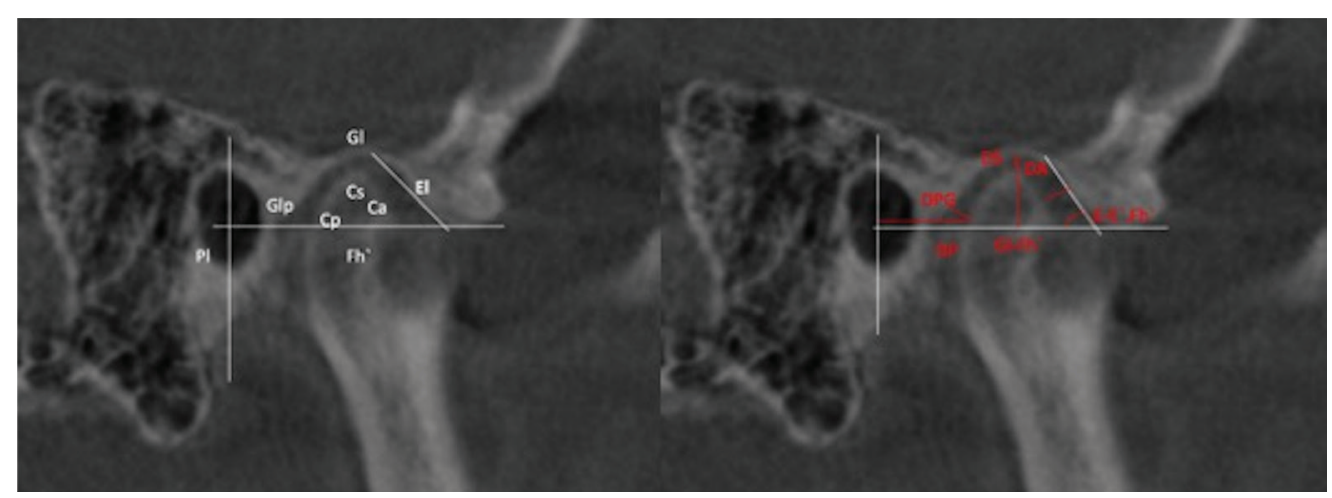

Fig. 3: Points, lines and planes analyzed. 
Table 3: Points and lines analyzed. Taken from de Arieta-Miranda JM et al. Spatial analysis of condyle position according to sagittal skeletal relationship, assessed by cone beam computed tomography. Prog Orthod. 2013;14(1):36.

\begin{tabular}{|l|}
\hline \multicolumn{1}{|c|}{ Reference points, lines and planes } \\
\hline Cs. The highest point of the condyle in the sagittal view. \\
\hline Gl. Most concave point in the glenoid fossa. \\
\hline Cp. Most convex point of the posterior face of the condyle. \\
\hline Ca. Point on the anterior wall of the condyle that is closest to the posterior wall of the articular eminence. \\
\hline El. Point on the posterior wall of the articular eminence that is closest to the anterior wall of the condyle. \\
\hline $\begin{array}{l}\text { Pl. Line perpendicular to the Frankfurt plane passing through the midpoint of the sagittal diameter of the external } \\
\text { auditory canal on its sagittal diameter. }\end{array}$ \\
\hline E-E'. Line tangential to the posterior wall of the articular eminence. \\
\hline Fh. Line parallel to the Frankfurt plane passing through the lower edge of the articular eminence. \\
\hline
\end{tabular}

Table 4: Analyzed measurements. Taken from Arieta-Miranda JM et al. Spatial analysis of condyle position according to sagittal skeletal relationship, assessed by cone beam computed tomography. Prog Orthod. 2013;14(1):36.

\begin{tabular}{|c|}
\hline Measurements registered \\
\hline $\begin{array}{l}\text { Anterior distance }(A D) \text { : measurement from the most anterior point of the condyle }(\mathrm{Ca}) \text { to the closest point on the } \\
\text { posterior wall of the articular eminence }(\mathrm{El}) \text {. }\end{array}$ \\
\hline $\begin{array}{l}\text { Posterior distance to the glenoid fossa (PDGF): measurement from the most posterior point of the condyle to the } \\
\text { closest point on the anterior wall of the glenoid fossa.. }\end{array}$ \\
\hline $\begin{array}{l}\text { Posterior distance }(P D): \text { most posterior point of the condyle to the PI line (line perpendicular to the Frankfurt plane } \\
\text { passing through the midpoint of the saggital plane of the external auditory canal). }\end{array}$ \\
\hline $\begin{array}{l}\text { Upper distance (UD): measurement from the highest point of the condyle (Cs) to the deepest point of the glenoid } \\
\text { fossa (GI). }\end{array}$ \\
\hline $\begin{array}{l}\text { Height of the glenoid fossa }(G l-F h) \text { : distance from the deepest point of the glenoid fossa and the plane parallel to the } \\
\text { Frankfurt plane passing through the lowest point of the articular eminence. }\end{array}$ \\
\hline $\begin{array}{l}\text { Angulation of the articular eminence (EE'Fh): angle formed by a tangential line to the posterior wall of the articu- } \\
\text { lar eminence (E-E') and the parallel plane to the Frankfurt plane passing through the lowest point of the articular } \\
\text { eminence (Fh). }\end{array}$ \\
\hline
\end{tabular}

\section{Results}

Table 5 shows the results obtained for the variables studied on each group. It should be noted that all the values are given in millimeters except for the angulation of the glenoid cavity (EE'Fh) that was registered in degrees. -Descriptive analysis of the condylar concentricity For the purpose of this study, a condyle is considered to have absolute concentricity if the formula described by Pullinger (32) equals to 0 . In order to increase the concentricity range, the above author and other authors afterwards, such as Song et al. (33) and Krisjane et al. (34), established as concentric those condyles that had a value between 0 and $12 \%$ using the same formula.

Therefore, a value smaller than -12 reflects a posterior position of the condyle, meanwhile a value greater than +12 indicates an anterior position of the condyle.

In the normal occlusion group, despite that no one in the study sample presented absolute concentricity, 55\% had both condyles concentric (values ranging between 0 and \pm 12 ), and $12,5 \%$ had only one condyle concentric. Therefore, $67.5 \%$ or the group with normal occlusion had condylar concentricity in at least one of the two condyles, (Table 6). Only $10 \%$ of the sample in groups I (class II/1) and II (class II/2) presented concentricity in both condyles (table 3). In class II/1 most condyles are positioned anteriorly in the fossa. On the other hand, class $\mathrm{II} / 2$ is the group that presented more condyles positioned posteriorly, (Table 7).

After analyzing the results, in the control group (normal occlusion) no statistically significant differences were found for both condyles in 5 out of 6 values analyzed. The only measurement that gave statistically significant differences was the Posterior Distance (PD).

To clarify this difference, two different posterior distances where analyzed: the posterior distance (PD) and the posterior distance to the glenoid fossa (PDGF). The $\mathrm{p}$ value for the posterior distance was 0.029 , which is considered statistically significant $(p<0.05)$. However, the $p$ 
Table 5: Description of the values and results analyzed.

\begin{tabular}{|c|c|c|c|c|c|c|c|c|c|c|}
\hline \multicolumn{11}{|c|}{ Descriptive statistics } \\
\hline & \multicolumn{2}{|c|}{ GROUP 0} & \multicolumn{2}{|c|}{ GROUP 1} & \multicolumn{2}{|c|}{ GROUP 2} & \multicolumn{2}{|c|}{ GROUP 3} & \multicolumn{2}{|c|}{ TOTAL } \\
\hline & \multicolumn{2}{|c|}{$\overline{\bar{X}}( \pm D E)$} & \multicolumn{2}{|c|}{$\overline{\bar{X}}( \pm D E)$} & \multicolumn{2}{|c|}{$\overline{\bar{X}}( \pm D E)$} & \multicolumn{2}{|c|}{$\overline{\bar{X}}( \pm D E)$} & \multicolumn{2}{|c|}{$\overline{\bar{X}}( \pm D E)$} \\
\hline & RIGHT & LEFT & RIGHT & LEFT & RIGHT & LEFT & RIGHT & LEFT & RIGHT & LEFT \\
\hline \multirow[t]{2}{*}{$\mathrm{AD}$} & 2.24 & 2.34 & 1.92 & 2.06 & 2.78 & 2.49 & 1.94 & 1.93 & 2.22 & 2.20 \\
\hline & $( \pm 0.58)$ & $( \pm 0.59)$ & $( \pm 0.69)$ & $( \pm 0.57)$ & $( \pm 1.02)$ & $( \pm 0.72)$ & $( \pm 0,79)$ & $( \pm 0,74)$ & $( \pm 0,85)$ & $( \pm 0,68)$ \\
\hline \multirow[t]{2}{*}{ SD } & 2.97 & 2.82 & 2.68 & 2.50 & 2.45 & 2.74 & 2.19 & 2.02 & 2.57 & 2.52 \\
\hline & $( \pm 0.93)$ & $( \pm 0.72)$ & $( \pm 0.86)$ & $( \pm 0.84)$ & $( \pm 0.87)$ & $( \pm 0.85)$ & $( \pm 1.15)$ & $( \pm 1.08)$ & $( \pm 0.99)$ & $( \pm 0.92)$ \\
\hline \multirow[t]{2}{*}{ PD } & 8.28 & 7.41 & 8.00 & 7.80 & 6.94 & 6.71 & 8.77 & 8.27 & 8.00 & 7.55 \\
\hline & $( \pm 1.18)$ & $( \pm 1.24)$ & $( \pm 1.38)$ & $( \pm 1.88)$ & $( \pm 1.52)$ & $( \pm 1.29)$ & $( \pm 1.49)$ & $( \pm 1.71)$ & $( \pm 1.53)$ & $( \pm 1.63)$ \\
\hline \multirow[t]{2}{*}{ PDGF } & 2.28 & 2.10 & 2.71 & 2.68 & 1.73 & 1.78 & 2.03 & 2.23 & 2.19 & 2,20 \\
\hline & $( \pm 0.61)$ & $( \pm 0.65)$ & $( \pm 0.75)$ & $( \pm 0.83)$ & $( \pm 0.42)$ & $( \pm 0.54)$ & $( \pm 0.82)$ & $( \pm 0.84)$ & $( \pm 0.75)$ & $( \pm 0.78)$ \\
\hline \multirow[t]{2}{*}{ Gl-Fh } & 7.30 & 7.23 & 7.13 & 6.93 & 6.60 & 7.16 & 6.71 & 6.81 & 6.94 & 7.03 \\
\hline & $( \pm 1.14)$ & $( \pm 1.40)$ & $( \pm 1.12)$ & $( \pm 0.96)$ & $( \pm 1.15)$ & $( \pm 1.30)$ & $( \pm 1.35)$ & $( \pm 1.17)$ & $( \pm 1.21)$ & $( \pm 1.21)$ \\
\hline \multirow[t]{2}{*}{ E-E'Fh'. } & 37.06 & 35.72 & 44.27 & 43.26 & 39.41 & 37.61 & 41.07 & 41.43 & 40.45 & 39.50 \\
\hline & $( \pm 4.49)$ & $( \pm 8.64)$ & $( \pm 7.86)$ & $( \pm 5.87)$ & $( \pm 5.61)$ & $( \pm 9.23)$ & $( \pm 6.71)$ & $( \pm 5.56)$ & $( \pm 6.71)$ & $( \pm 7.95)$ \\
\hline
\end{tabular}

Table 6: Analysis of the condylar concentricity in the normal occlusion group.

The values highlighted in red show that the condyle is concentric.

\begin{tabular}{|c|c|}
\hline \multicolumn{2}{|c|}{ Condylar concentricity in the normal occlusion group } \\
\hline LEFT CONDYLE & RIGHT CONDYLE \\
\hline 7.44 & 17.01 \\
\hline 5.04 & 3.48 \\
\hline-0.8 & 27.4 \\
\hline 6.0 & 6.9 \\
\hline-52 & -20.61 \\
\hline 13.08 & 5.7 \\
\hline-17.7 & -30.43 \\
\hline 5.1 & 7 \\
\hline 30 & 33.3 \\
\hline-4.1 & 3.5 \\
\hline-16 & 4.8 \\
\hline-1.7 & 9.7 \\
\hline 1.3 & -1.1 \\
\hline-60 & -19.69 \\
\hline-2.7 & 11.8 \\
\hline 6.5 & 2.09 \\
\hline 1.2 & -7.7 \\
\hline 10.9 & 6.4 \\
\hline 4.5 & -12.5 \\
\hline-3.1 & -2.46 \\
\hline
\end{tabular}


Table 7: Analysis of the condylar concentricity in the groups with malocclusion.

\begin{tabular}{|c|c|c|c|c|c|}
\hline \multicolumn{6}{|c|}{ Condylar concentricity } \\
\hline \multirow{2}{*}{\multicolumn{2}{|c|}{$\begin{array}{c}\text { GROUP I } \\
\text { CLASS II/1 }\end{array}$}} & \multirow{2}{*}{\multicolumn{2}{|c|}{$\begin{array}{c}\text { GROUP II } \\
\text { CLASS II/2 }\end{array}$}} & \multirow{2}{*}{\multicolumn{2}{|c|}{$\begin{array}{l}\text { GROUP III } \\
\text { CLASS III }\end{array}$}} \\
\hline & & & & & \\
\hline LEFT & RIGHT & LEFT & RIGHT & LEFT & RIGHT \\
\hline CONDYLE & CONDYLE & CONDYLE & CONDYLE & CONDYLE & CONDYLE \\
\hline 24.19 & -16.68 & -15.64 & -47.72 & 30.60 & 6.80 \\
\hline-33.33 & -37.52 & 13.44 & -27.93 & 51.65 & 33.33 \\
\hline 56.2 & 49.75 & -13.37 & 15.24 & -32.56 & 10.90 \\
\hline 44.98 & 33.85 & -35.78 & -37.11 & -26.25 & -32.95 \\
\hline 0 & 22.80 & -16.49 & -57.35 & 0.30 & -13.86 \\
\hline 19.53 & 7.29 & 19.23 & 8.09 & -9.20 & -24 \\
\hline 0 & 35.85 & -33.62 & -2.11 & 3.70 & -2.66 \\
\hline 23.46 & 26.17 & -5.88 & 4.46 & -6.99 & -15.18 \\
\hline-23.85 & -23.34 & -8.27 & -5.60 & 3.86 & -24.92 \\
\hline 24.91 & 23.10 & -11.07 & -28.94 & 41.74 & 38.29 \\
\hline 0 & 7.64 & 14.86 & -7.98 & -15.44 & -25.70 \\
\hline 12 & 17.21 & -23.40 & -31.19 & 6.64 & 14.47 \\
\hline 33.47 & 23.53 & -42.96 & -12.71 & -2.32 & 8.79 \\
\hline 8.22 & 15.81 & -29.33 & -14.85 & 8.85 & 3.05 \\
\hline-1.44 & 44.35 & -41.40 & -55.38 & 0 & 0.33 \\
\hline 15.22 & 23.17 & -59.82 & -23.67 & 45.53 & 20.99 \\
\hline 12.80 & 39.45 & -16.39 & -8.12 & 4.32 & 3.08 \\
\hline-11.87 & 23.85 & 20.81 & 7.08 & 7.85 & 32.92 \\
\hline 34.07 & 16.48 & -11.11 & -36.12 & 24.38 & 22.48 \\
\hline 2.97 & 5.41 & -22.90 & -42.75 & 1.67 & -14.08 \\
\hline
\end{tabular}

value for the posterior distance to the glenoid fossa was 2.10 for the left condyle and 2.28 for the right one, and it was established that there was no statistically significant difference between both condyles ( $p>0.05)$, (Table 8 ). Afterwards, the values obtained for each variable in each malocclusion group were analyzed. Statistically significant differences were found between the different groups when analyzing the Anterior Distance (AD); these differences were on the right condyle, (Table 9).

Like in the normal occlusion group, two different measurements were analyzed to determine the posterior distance of the condile. Statistically significant measurements can be found between some of the groups (Tables $10,11)$ in both measurements.

The analysis of the superior distance and the depth of the fossa are the two measurements that where less statistically significant differences have been found (Tables 12,13).

Finally, in the analysis of the angulation of the glenoid fossa (Table 14) both groups 0 and 1 seem to be statistically significant with the same value for both condyles and on the same when comparing groups 0 and 1 .

\section{Discussion}

The position of the condyle within the glenoid fossa is still controversial, despite the improvements in the diagnostic methods. After reviewing the existing literature, it could be said that many researchers associate the lack of concentricity with internal temporomandibular disorders.

As described by Kurusu et al. (35), occlusal forces can modify condylar morphology. Therefore, it is important to know the morphology and the condyle-fossa relationship in the asymptomatic group with an ideal occlusion, as it can be used as a guideline for future diagnosis and treatment planning in patients with malocclusion. When analyzing the asymptomatic control group with normal occlusion, no significant differences were found between both condyles in five out of six measurements taken; only the posterior distance was significantly different.

As explained in the article written by Miranda et al. (11), the posterior distance that uses as reference a perpendicular line to the Frankfurt plane that goes through the midpoint of the external auditory canal, could lead to 
Table 8: Quantitative analysis of the control group with normal occlusion.

\begin{tabular}{|c|c|c|c|c|}
\hline \multicolumn{5}{|c|}{ Control group or normal occlusion } \\
\hline & $\begin{array}{c}\text { RIGHT } \\
\text { CONDYLE }\end{array}$ & $\begin{array}{c}\text { LEFT } \\
\text { CONDYLE }\end{array}$ & $\begin{array}{c}\text { STATISTICS } \\
(\mathrm{t})\end{array}$ & P VALUE \\
\hline DA & $2.23 \mathrm{~mm}$ & $2.34 \mathrm{~mm}$ & 0.58 & 0.560 \\
\hline DS & $2.96 \mathrm{~mm}$ & $2.82 \mathrm{~mm}$ & -0.55 & 0.584 \\
\hline DP & $8.27 \mathrm{~mm}$ & $7.40 \mathrm{~mm}$ & $\mathbf{- 2 . 2 6}$ & $\mathbf{0 . 0 2 9}$ \\
\hline PDGF & $2.28 \mathrm{~mm}$ & $2.10 \mathrm{~mm}$ & -0.89 & 0.374 \\
\hline GLFH & $7.30 \mathrm{~mm}$ & $7.22 \mathrm{~mm}$ & -0.18 & 0.856 \\
\hline EEFH & $37.05^{\circ}$ & $35.72^{\circ}$ & -0.61 & 0.545 \\
\hline
\end{tabular}

Table 9: Comparison of the results obtained for each group for the anterior distance. Reference value ${ }^{*} p<0.05,{ }^{*} * p<0.005$.

\begin{tabular}{|l|c|c|c|}
\hline \multicolumn{4}{|c|}{ Anterior distance } \\
\hline \multicolumn{2}{|c|}{} & $\begin{array}{c}\text { RIGHT } \\
P \text { VALUE }\end{array}$ & $\begin{array}{c}\text { LEFT } \\
P \text { VALUE }\end{array}$ \\
\hline GROUP 0 & GROUP 1 & 1.000 & 1.000 \\
\hline \multirow{2}{*}{} & GROUP 2 & 0.199 & 1.000 \\
\cline { 2 - 4 } & GROUP 3 & 1.000 & 0.311 \\
\hline GROUP 1 & GROUP 0 & 1.000 & 1.000 \\
\hline \multirow{2}{*}{} & GROUP 2 & $0.006^{*}$ & 0.263 \\
\cline { 2 - 4 } & GROUP 3 & 1.000 & 1.000 \\
\hline & GROUP 0 & 0.199 & 1.000 \\
\cline { 2 - 4 } & GROUP 1 & $0.006^{* *}$ & 0.263 \\
\hline GROUP 3 & GROUP 3 & $0.007^{*}$ & 0.059 \\
\hline & GROUP 1 & 1.000 & 0.311 \\
\cline { 2 - 4 } & GROUP 2 & $0.007^{*}$ & 0.059 \\
\hline
\end{tabular}

Table 10: Comparison of the different results obtained for the posterior distance. Reference value ${ }^{*} p<0.05,{ }^{* *} p<0.005$.

\begin{tabular}{|l|c|c|c|}
\hline \multicolumn{2}{|c|}{} & $\begin{array}{c}\text { RIGHT } \\
\text { P VALUE }\end{array}$ & $\begin{array}{c}\text { LEFT } \\
\text { P VALUE }\end{array}$ \\
\hline GROUP 0 & GROUP 1 & 1.000 & 1.000 \\
\hline \multirow{2}{*}{} & GROUP 2 & $0.021^{*}$ & 0.948 \\
\cline { 2 - 4 } & GROUP 3 & 1.000 & 0.498 \\
\hline GROUP 1 & GROUP 0 & 1.000 & 1.000 \\
\hline \multirow{3}{*}{} & GROUP 2 & 0.112 & 0.178 \\
\cline { 2 - 4 } & GROUP 3 & 0.527 & 1.000 \\
\hline & GROUP 0 & $0.021^{*}$ & 0.948 \\
\hline & GROUP 1 & 0.112 & 0.178 \\
\cline { 2 - 4 } & GROUP 3 & $0.001^{* *}$ & $0.013^{*}$ \\
\hline GROUP 3 & GROUP 0 & 1.000 & 0.498 \\
\hline & GROUP 1 & 0.527 & 1.000 \\
\cline { 2 - 4 } & GROUP 2 & $0.001^{* *}$ & $0.013^{*}$ \\
\hline
\end{tabular}

Table 11: Comparison of the results obtained in the posterior distance to the glenoid fossa. Reference value $* p<0.05, * * p<0.005$.

\begin{tabular}{|c|c|c|c|}
\hline \multicolumn{3}{|c|}{ Posterior distance to the glenoid fossa } \\
\hline \multicolumn{2}{|c|}{} & $\begin{array}{c}\text { RIGHT } \\
\text { P VALUE }\end{array}$ & $\begin{array}{c}\text { LEFT } \\
\text { P VALUE }\end{array}$ \\
\hline GROUP 0 & GROUP 1 & 0.289 & 0.084 \\
\hline & GROUP 2 & 0.064 & 1.000 \\
\cline { 2 - 4 } & GROUP 3 & 1.000 & 1.000 \\
\hline GROUP 1 & GROUP 0 & 0.289 & 0.084 \\
\hline \multirow{3}{*}{} & GROUP 2 & $0.000^{* *}$ & $0.001^{* *}$ \\
\cline { 2 - 4 } & GROUP 3 & $0.012^{*}$ & 0.317 \\
\hline GROUP 2 & GROUP 0 & 0.064 & 1.000 \\
\hline \multirow{2}{*}{ GROUP 3 } & GROUP 1 & $0.000^{* *}$ & $0.001^{* *}$ \\
\cline { 2 - 4 } & GROUP 3 & 0.967 & 0.317 \\
\hline & GROUP 0 & 1.000 & 1.000 \\
\cline { 2 - 4 } & GROUP 1 & $0.012^{*}$ & 0.317 \\
\hline
\end{tabular}

Table 12: Comparison of the obtained results in the superior distance. Reference value $* p<0,05,{ }^{* *} p<0,005$.

\begin{tabular}{|c|c|c|c|}
\hline \multicolumn{4}{|c|}{ Upper distance } \\
\hline \multicolumn{2}{|c|}{} & $\begin{array}{c}\text { RIGHT } \\
\text { P VALUE }\end{array}$ & $\begin{array}{c}\text { LEFT } \\
\text { P VALUE }\end{array}$ \\
\hline GROUP 0 & GROUP 1 & 1.000 & 1.000 \\
\hline & GROUP 2 & 0.544 & 1.000 \\
\cline { 2 - 4 } & GROUP 3 & 0.073 & $0.031^{*}$ \\
\hline GROUP 1 & GROUP 0 & 1.000 & 1.000 \\
\hline \multirow{3}{*}{ GROUP 2 } & GROUP 2 & 1.000 & 1.000 \\
\cline { 2 - 4 } & GROUP 3 & 0.655 & 0.527 \\
\hline & GROUP 0 & 0.544 & 1.000 \\
\cline { 2 - 4 } & GROUP 3 & 1.000 & 1.000 \\
\hline GROUP 3 & GROUP 0 & 1.000 & 0.070 \\
\hline & GROUP 1 & 0.655 & $0.031^{*}$ \\
\cline { 2 - 4 } & GROUP 2 & 1.000 & 0.527 \\
\hline
\end{tabular}


Table 13: Comparison of the results obtained in the depth of the glenoid fossa. Reference value $* p<0.05, * * p<0.005$.clusion.

\begin{tabular}{|c|c|c|c|}
\hline \multicolumn{4}{|c|}{ Glenoid fossa depth } \\
\hline \multicolumn{2}{|c|}{} & $\begin{array}{c}\text { RIGHT } \\
\text { P VALUE }\end{array}$ & $\begin{array}{c}\text { LEFT } \\
\text { P VALUE }\end{array}$ \\
\hline GROUP 0 & GROUP 1 & 1.000 & 1.000 \\
\hline \multirow{3}{*}{} & GROUP 2 & 0.409 & 1.000 \\
\cline { 2 - 4 } & GROUP 3 & 0.730 & 1.000 \\
\hline GROUP 1 & GROUP 0 & 1.000 & 1.000 \\
\hline \multirow{3}{*}{ GROUP 2 } & GROUP 2 & 0.996 & 1.000 \\
\cline { 2 - 4 } & GROUP 3 & 1.000 & 1.000 \\
\hline & GROUP 0 & 0.409 & 1.000 \\
\cline { 2 - 4 } & GROUP 1 & 0.996 & 1.000 \\
\hline GROUP 3 & GROUP 0 & 1.000 & 1.000 \\
\hline & GROUP 1 & 0.730 & 1.000 \\
\cline { 2 - 4 } & GROUP 2 & 1.000 & 1.000 \\
\hline
\end{tabular}

Table 14: Comparison of the results obtained in the angulation of the glenoid fossa. Reference value $* p<0.05,{ }^{* *} p<0.005$.

\begin{tabular}{|l|l|c|c|}
\hline \multicolumn{4}{|c|}{ Angulation of the glenoid fossa } \\
\hline \multicolumn{2}{|c|}{} & $\begin{array}{c}\text { RIGHT } \\
P \text { VALUE }\end{array}$ & $\begin{array}{c}\text { LEFT } \\
P \text { VALUE }\end{array}$ \\
\hline GROUP 0 & GROUP 1 & $0.003^{* *}$ & $0.013^{*}$ \\
\hline \multirow{3}{*}{ GROUP 1 } & GROUP 2 & 1.000 & 1.000 \\
\cline { 2 - 4 } & GROUP 3 & 0.281 & 0.111 \\
\hline \multirow{3}{*}{ GROUP 0 } & $0.003^{* *}$ & $0.013^{*}$ \\
\hline & GROUP 2 & 0.102 & 0.119 \\
\cline { 2 - 4 } & GROUP 3 & 0.675 & $1 . .000$ \\
\hline \multirow{3}{*}{ GROUP 0 } & 1.000 & 1.000 \\
\cline { 2 - 4 } & GROUP 1 & 0.102 & 0.119 \\
\hline \multirow{2}{*}{ GROUP 3 } & 1.000 & 0.667 \\
\hline & GROUP 0 & 0.281 & 0.111 \\
\cline { 2 - 4 } & GROUP 1 & 0.675 & 1.000 \\
\hline
\end{tabular}

error due to its morphology and position. To solve this possible error, the current study incorporates the posterior distance to the glenoid fossa.

Five reference measurements were found on this study for which no significant differences were found between both joints. These results match the ones provided by Wang et al. (36) when analyzing healthy adults. These values were established as a reference point when analyzing the different sagittal malocclusions.

The greater differences compared to other studies were found when analyzing the depth of the fossa. The results of this study are similar to those described by Miranda et al. (11), which is not surprising as it uses the same measuring protocol. However, the results of this study do differ from those of authors such as Vitral et al. (37), Song et al. (33) or Ganugapanta et al. (38), which may be related to the use of a different measuring protocol. With regards to the condylar concentricity analyzed using the formula described by Pullinger and Hollender, the normal occlusion group is the one with the largest number of concentric condyles. When studying asymptomatic patients 25 , these authors described between 50 and $65 \%$ of concentric condyles, results that are similar to those obtained in the present study, which were $67.5 \%$ concentricity.

Therefore, an association can be made between the high percentage of concentricity of the asymptomatic group with a normal occlusion and a normal function of the TMJ. This theory is supported by authors such as Weinberg (24) y Gerber (35), who have previously linked the condylar concentricity and a normal function of the TMJ.

To determine the spatial relation of the condyle within the glenoid fossa on a sagittal level, the first step was to compare the anterior and posterior distance between the different groups. As exhibited on the results, class II/1 and class III groups have smaller values for the anterior distance, reflecting a more anterior position of the condyle; meanwhile, the class II/2 group has the condyle in a more posterior position. The normal occlusion group displayed intermediate values.

The analysis of the Posterior Distance values provided significant differences between the normal occlusion group and class II $/ 2$, and between class $\mathrm{II} / 2$ and class III groups. These results agree with those found for the Anterior Distance.

Class III group has an anterior distance similar to Class II/1 group; no statistically significant differences were found, although the posterior distance is greater in class III patients. These results may be linked with the condyle size or the morphology of the glenoid fossa.

These findings back the theory initially described by Thompson (2) in the 80s. He described a posterior displacement in the condylar position in classes II/2 due to a lack of overjet. More recent studies such as Katsavrias y Halazonetis (39) or Zhou et al. (40) have observed a more posterior position in the class $\mathrm{II} / 2$ group.

On the contrary, authors such as Gianelly and Cohlmia et al. (39) found concentric condyles in class II/2 patients. None of these studies could have used CBCT technology due to the date they were carried out on.

Similar results to the ones of this study were found by Song et al. (33), where class I, II/1 and III subjects were found to have a mainly anterior and concentric position of the condyle. Class II/2 had a mainly posterior and concentric position of the condyle. Merigue et al. (42) and Uzel et al. (43) also described a larger number of 
condyles anteriorly positioned in the class II/1 groups they studied. Krisjane et al. (34) also described anterior and concentric positions for class II/1 y III groups.

To complete the sagittal analysis of the condylar position, the obtained values were added using the condylar concentricity analysis formula described by Pullinger and Hollender (34). Similarly, to Cohlmia et al. (44), no patients were found to have both condyles in absolute concentricity, but there were multiple condyles within the range considered as concentric.

Class II/ 1 and class II/2 groups have $27,5 \%$ of concentric condyles; this percentage was $45 \%$ in class III group.

The percentage of condyles that did not present concentricity seemed to be positioned anteriorly in the glenoid fossa for class II/1 and class III, with this fact being more noticeable in class II/1 group. The group with malocclusion II/2 seemed to have more condyles posteriorly positioned in the fossa.

The Upper Distance was analyzed to determine the condylar position on a vertical level in all groups, and the results were compared. Class III group had higher condyle position within the fossa. However, when compared to the other groups, significant differences were only found compared to the normal occlusion group. These results agree with those of authors such as Kaur et al. and Song et al. (33), who described a higher condyle position in class III patients.

Katsavrias and Halazonetis (40), which, as previously said, described a more posterior position in class II/2 patients, also established a more anterior position for class II/ 1 and a higher position in class III. All of their results back the results of this study.

With regards to the morphology of the fossa, its depth and angulation was analyzed following the procedure of Katsavrias and Halazonetis (40). No statistically significant differences were found between any of the studied groups for the studied values to determine the depth of the glenoid fossa. These results do not match those of authors such as Miranda et al. (11), Song et al. (33) y Katsavrias y Halazonetis (40), as they described a smaller fossa depth in class III patients.

The results obtained when analyzing the angulation of the fossa showed statistically significant differences only between the normal occlusion group and the class II/1 group, with classes II/1 displaying a larger angle.

\section{Conclusions}

1. The normal malocclusion group has a more intermediate position of the condyle within the fossa and a greater percentage of condylar concentricity. The initial hypothesis of this study is supported by this: the optimal position of the condyle would be an intermediate and concentric position within the glenoid fossa.

2. Despite not all of the comparisons between the measurements being statistically significant, they did all su- pport this conclusion: class II/1 and class III malocclusion groups have a more anteriorly positioned condyle compared to class II/2 group, where the condyle is in a more posterior position.

3. Although it was only statistically significant when comparing the normal occlusion and the class III groups: class III patients have the higher condyles position within the glenoid fossa.

4. With regards to the glenoid fossa morphology, no statistically significant differences were found in the depth of the fossa between any of the studied malocclusions. In terms of the angulation of the fossa, Class II/ 1 presented a greater angle (these results were statistically significant when compared to the normal occlusion control group).

\section{References}

1. Pordes F. Roentgenography of the Mandibulo-Temporal Articulation From Direct Frontal Direction. Dent Cosm. 1916;58:1426.

2. Updegrave WJ. An Evaluation of Temporomandibular Joint Roentgenography. J Am Dent Assoc. 1953;46(4):408-19.

3. Linblom G. Technique for roentgen-photographic registration of the different condyle positions in the temporomandibular joint. Dent Cosm. 1936;78:1227-35.

4. B. Holly Broadbent. A new X-Ray technique and its application to orthodontia. Angle Orthod. 1931;1:45-66

5. Gillis R. Roentgen Ray Study of the Temporomandibular Articulation. J Am Dent Assoc. 1935;22:1321-8.

6. Reisner SE. Temporomandibular reactions to Occlusal Anomalies. J Am Dent Assoc. 1938;24:1938-53.

7. Brader AC. The application of the prinicples of cephalometric laminagraphy to studies of the frontal planes of the human head. Am J Orthod. 1949;35:249-68.

8. Ricketts RM. Various conditions of the temporomandibular joint as revealed by cephalometric laminagraphy. Angle Orthod. 1952;22:98115.

9. Ricketts RM. A study of changes in temporomandibular joint, relations associate with the treatment of class II malocclusion (Angle). Am J Orthod. 1952;38:918-33.

10. Ricketts RM. Variations of the Temporomandibular joint as revealed by cephalometric laminagraphy. Am J Orthod. 1950;36:877-98.

11. Arieta-Miranda JM, Silva-Valencia M, Flores-Mir C, Paredes-Sampen NA, Arriola-Guillen LE. Spatial analysis of condyle position according to sagittal skeletal relationship, assessed by cone beam computed tomography. Prog Orthod. 2013;14:36.

12. Scarfe W, Azevedo B, Toghyani S, Farman A. Cone Beam Computed Tomographic imaging in orthodontics. Aust Dent J. 2017;62:33-50. 13. Lee TY, Kim KH, Yu HS, Kim KD, Jung YS, Baik HS. Correlation analysis of three-dimensional changes of hard and soft tissues in class III orthognathic surgery patients using cone-beam computed tomography. J Craniofac Surg. 2014;25:1530-40.

14. Sahin O, Kalabalik F, Tatar B, Odabasi O. Cone-Beam Computed Tomographic Evaluation of Styloid Process in Patients With Temporomandibular Disorders and Asymptomatic Individuals. J Craniofac Surg. 2019;30:2236-8.

15. Paesani D, Salas E, Martinez A, Isberg A. Prevalence of temporomandibular joint disk displacement in infants and young children. Oral Surg Oral Med Oral Pathol Oral Radiol Endodontology. 1999;87:15-9. 16. Ahn SJ, Kim TW, Lee DY, Nahm DS. Evaluation of internal derangement of the temporomandibular joint by panoramic radiographs compared with magnetic resonance imaging. Am J Orthod Dentofacial Orthop. 2006;129:479-85.

17. Tasaki MM, Westesson PL, Isberg AM, Ren YF, Tallents RH. Classification and prevalence of temporomandibular joint disk displacement in patients and symptom-free volunteers. Am J Orthod Dentofacial Orthop. 1996;109:249-62. 
18. Sutton DI, Sadowsky PL, Bernreuter WK, McCutcheon MJ, Lakshminarayanan AV. Temporomandibular joint sounds and condyle/disk relations on magnetic resonance images. Am J Orthod Dentofacial Orthop. 1992;101:70-8.

19. Imanimoghaddam M, Madani AS, Mahdavi P, Bagherpour A, Darijani M, Ebrahimnejad H. Evaluation of condylar positions in patients with temporomandibular disorders: A cone-beam computed tomographic study. Imaging Sci Dent. 2016;46:127-31.

20. Thompson John R. Abnormal function of the temporomandibular joints and related musculature. Angle Orthod. 1986;56:143-63.

21. Thompson John R. Abnormal function of the temporomandibular joints and related musculature Part II. Angle Orthod. 1986;56:181-92.

22. Lindblom, G. Disorders of the temporomandibular joint, causal factors and the value of temporomandibular radiographs in their diagnosis and therapy. Acta Odontol Scand. 1953;11:61.

23. Rokni A, Ismail YH. Radiographic comparative study of condylar position in centric relation and centric occlusion. J Prosthet Dent. 1979;41:395.

24. Weinberg LA. Role of condylar position in TMJ dysfunction-pain syndrome. J Prosthet Dent. 1979;41:636-43.

25. Pullinger AG, Hollender L, Solberg WK, Petersson A. A tomographic study of mandibular condyle position in an asymptomatic population. J Prosthet Dent. 1985;53:706-13.

26. Pullinger AG, Solberg WK, Hollender L, Guichet D. Tomographic analysis of mandibular condyle position in diagnostic subgroups of temporomandibular disorders. J Prosthet Dent. 1986;55:723-9.

27. Cholasueksa P, Warita H, Soma K. Alterations of the Rat Temporomandibular Joint in Functional Posterior Displacement of the Mandible. Angle Orthod. 2004;74:7.

28. Incesu L, Taşkaya-Yılmaz N, Ögütcen-Toller M, Uzun E. Relationship of condylar position to disc position and morphology. Eur J Radiol. 2004;51:269-73.

29. Rodrigues AF, Fraga MR, Vitral RWF. Computed tomography evaluation of the temporomandibular joint in Class I malocclusion patients: Condylar symmetry and condyle-fossa relationship. Am J Orthod Dentofacial Orthop. 2009;136:192-8.

30. Rodrigues AF, Fraga MR, Vitral RWF. Computed tomography evaluation of the temporomandibular joint in Class II Division 1 and Class III malocclusion patients: Condylar symmetry and condyle-fossa relationship. Am J Orthod Dentofacial Orthop. 2009;136:199-206.

31. Pita Fernández, S, Pértegas Díaz, S. La fiabilidad de las mediciones clínicas: el análisis de la concordancia para variables numéricas. 32. Pullinger A, Hollender L. Variation in condyle-fossa relationships according to different methods of evaluation in tomograms. Oral Surg Oral Med Oral Pathol. 1986;62:719-27.

33. Song J, Cheng M, Qian Y, Chu F. Cone-beam CT evaluation of temporomandibular joint in permanent dentition according to Angle's classification. Oral Radiol. 2019;36:261-266.

34. Krisjane Z, Urtane I, Krumina G, Zepa K. Three-dimensional evaluation of TMJ parameters in Class II and Class III patients. Stomatologija. 2009;11:32-6.

35. Kurusu A, Horiuchi M, Soma K. Relationship between Occlusal Force and Mandibular Condyle Morphology: Evaluated by Limited Cone-Beam Computed Tomography. Angle Orthod. 2009;79:1063-9.

36. Rui-yong Wang, Ma XC, Zhang WL, Liu DG. Investigation of temporomandibular joint space of healthy adults by using cone beam computed tomography. J Peking Univ Health Sci. 2007;39:503-6.

37. Vitral RWF, da Silva Campos MJ, Rodrigues AF, Fraga MR. Temporomandibular joint and normal occlusion: Is there anything singular about it? A computed tomographic evaluation. Am J Orthod Dentofacial Orthop.2011;140:18-24.

38. Ganugapanta VR. Computed Tomographic Evaluation of Condylar Symmetry and Condyle-Fossa Relationship of the Temporomandibular Joint in Subjects with Normal Occlusion and Malocclusion: A Comparative Study. J Clin Diagn Res. 2017;11:29-33.

39. Katsavrias EG, Halazonetis DJ. Condyle and fossa shape in Class II and Class III skeletal patterns: A morphometric tomographic study. Am J Orthod Dentofacial Orthop.2005;128:337-46.

40. Zhou D, Hu M, Liang D, Zhao G, Liu A. Relationship between fossa-condylar position, meniscus position, and morphologic change in patients with Class II and III malocclusion. Chin J Dent Res. 1999;2:45-9.

41. Gianelly AA, Petras JC, Boffa J. Condylar position and Class II deep-bite, no-overjet malocclusions. Am J Orthod Dentofacial Orthop. 1989;96:428.

42. Merigue LF, Conti AC de CF, Oltramari-Navarro PVP, Navarro R de L, Almeida MR de. Tomographic evaluation of the temporomandibular joint in malocclusion subjects: condylar morphology and position. Braz Oral Res. 2016;30:1-7.

43. Uzel A, Özyürek Y, Öztunç H. Condyle position in Class II Division 1 malocclusion patients: Correlation between MPI records and CBCT images. J World Fed Orthod. 2013;2:65-70.

44. Cohlmia Jeff T, Grosh Joydeep, Nanda Ram S. Tomographic assessment of temporomandibular joints in patients with malocclusion. Angle Orthod. 1996;66:27-36.

45. Kaur A, Natt AS, Mehra SK, Maheshwari K, Kaur A. Improved Visualization and Assessment of Condylar Position in the Glenoid Fossa for Different Occlusions: A CBCT Study. J Contemp Dent Pract. 2016;17:679-86.

\section{Conflict of interest}

Non declared. 